\title{
Primary caregivers attitude towards patients with mental illness: a survey study in psychiatric centre, SMS medical college, Jaipur, Rajasthan, India
}

\author{
Tulika Sharma ${ }^{1 *}$, Dr. Paramjeet Singh ${ }^{2}$, Dr. Himanshu Phulwari ${ }^{3}$
}

\section{ABSTRACT}

The purpose of the present study was to find out the attitudes of primary caregivers towards mental illness. The hypothesis was "there would be a significant difference in the attitude of primary caregivers towards mental illness by people belonging to rural and urban areas." The sample consists of 50 subjects ( 25 females and 25 males out of it, 25 were from the rural population \& 25 were from the urban population). The age group consists of the participants was from 18 years to 65 years, and their education qualification was not an obligation. Personal data consist of demographic information was also collected. The scale "The Community Attitudes Towards Mental Illness scale (CAMI)" was developed by Taylor and Dear in 1981, was used to assess the attitude towards mental illness of the subjects. For statistical analysis, correlation and student $t$-test were used for the p-value and to found the differences in the attitudes of primary caregivers. The results showed variances in the primary caregivers' attitudes between the rural area and the urban area.

Keywords: Attitude, Primary Care-Givers, Mental Illness, Rural, Urban

$\mathrm{T}$ The World Health Organization (WHO) defines mental health as "A state of wellbeing in which the individual realizes his or her abilities, can cope with the normal stresses of life, can work productively and fruitfully, and can make a contribution to his or her community."

The Diagnostic and Statistical Manual of Mental Disorders by the American Psychiatric Association (DSM-5) proposes the definition of mental/psychiatric disorder or mental illness.

\section{Features}

A. a behavioral or psychological syndrome or pattern that occurs in an individual

\footnotetext{
${ }^{1}$ Postgraduate Student of Psychology, Panjab University, Chandigarh, India

${ }^{2}$ HOD \& Senior Professor, SMS Medical College, Jaipur, India

${ }^{3}$ Doctor of Medicine Student, SMS Medical College, Jaipur, India

*Responding Author
}

Received: February 19, 2021; Revision Received: March 16, 2021; Accepted: March 28, 2021

(C) 2021, Sharma T., Singh P. \& Phulwari H.; licensee IJIP. This is an Open Access Research distributed under the terms of the Creative Commons Attribution License (www.creativecommons.org/licenses/by/2.0), which permits unrestricted use, distribution, and reproduction in any Medium, provided the original work is properly cited. 
B. the consequences of which are clinically significant distress (e.g., a painful symptom) or disability (i.e., impairment in one or more crucial areas of functioning)

C. must not be merely an expectable response to relative stressors and losses (for example, the loss of a loved one) or a culturally sanctioned response to a particular event (for example, trance states in religious rituals)

D. that reflects an underlying psychobiological dysfunction

E. that is not solely a result of social deviance or conflicts with society

F. that has diagnostic validity using one or more sets of diagnostic validators (e.g., prognostic significance, psychobiological disruption, response to treatment)

G. that has clinical utility (for example, contributes to better conceptualization of diagnosis basis, or better assessment and treatment)

\section{Other Considerations}

H. no definition specifies precise boundaries for the concept of either "medical disorder" or "mental disorder" in it

I. diagnostic validators and clinical utility should help differentiate a disorder from diagnosing "nearest neighbors" of it

J. when considering whether to add a psychiatric condition to the nomenclature, or delete a psychiatric state from a nomenclature, potential benefits (for example, provide better patient care, stimulate new research) should outweigh potential harms (for example, hurt particular individuals, be subject to misuse).

\section{Traditional Classification System: -7 common categories}

For many years, systems of classification have grouped disorders into seven major categories.

1. Mood disorders

2. Anxiety disorders

3. Personality disorders

4. Psychotic disorders

5. Eating disorders

6. Trauma-related disorders

7. Substance abuse disorders.

\section{Mental illnesses in India}

Mental illness can affect the normal equilibrium of a person's thoughts, behavior, and emotions. Irrespective of gender, sexuality, social and economic location, mental illness can impact at any point.

As per the National Mental Health Survey (NMHS, 2016), one in ten people lives with depression in India, in which clinical depression is on top of the list. Anxiety disorders affect 3.6 of the population in the country. The most common forms of it include - Generalized anxiety disorder (GAD), Obsessive-compulsive disorder (OCD), Panic disorders, Social anxiety disorder (SAD), Phobias.

Stigma is attached to mental illness associated negative view towards the person.

Goffman (1963) states that a stigma is "an attribute that is deeply discrediting" that reduces someone "from a whole and usual person to a tainted, discounted one." 


\section{Primary caregivers attitude towards patients with mental illness: a survey study in psychiatric centre, SMS medical college, Jaipur, Rajasthan, India}

Dudley (2000) defined a stigma as stereotypes or negative views attributed to persons or groups of people when their characteristics or behaviors are viewed differently from or inferior to societal norms.

There are various dimensions of a stigma are-

- Dimension 1: Peril, otherwise known as dangerousness.

- Dimension 2: Aesthetics or the displeasing nature of mental disorders.

- Dimension 3: Origin, belief that mental disorders generate from biological factors

- Dimension 4: Pity, in which disorders that pitied to a greater degree are often less stigmatized

- Dimension 5: Concealability, or visibility of the illness

- Dimension 6: Course and stability question how likely the person with the disability is to recover and benefit from treatment.

- Dimension 7: The disruptiveness dimension assesses how much a mental or behavioral disorder may impact relationships or success in society

Attitude is the manner, disposition, feeling, and position about a person or thing, tendency, or orientation, especially in their mind.

According to Gordon Allport, "An attitude is a mental and neural state of readiness, organized through experience, exerting a directive or dynamic influence upon the individual's response to all objects and situations with which it is related."

Thurstone said, "An attitude denotes the total of man's inclinations and feelings, prejudice or bias, preconceived notions, ideas, fears, threats, and other specific topics."

Anastasi defined attitude as "A tendency to react favorably or unfavorably towards a designated class of stimuli, such as a national or racial group, a custom or an institution."

Attitude can be fall under two headings- explicit and implicit. The former category explains attitudes are that we are consciously aware of and that influence our behaviors and beliefs. Implicit attitudes are unconscious but still affect our belief system and our actions.

\section{Among the various factors that influence the formation of attitudes are:}

1. Personal experiences have left a strong impression.

2. Culture emphasized the influence of the environment (including culture) in shaping one's attitude.

3. Educational Institutions. As a system, educational institutions have a strong influence in shaping attitudes because they lay the foundation of understanding.

4. Religious background develops moral concepts within the individual.

Caregiving is the practice of providing possible care and support to an intimate relationship partner. Caregiving behavior focuses on the decrement of the distress level and supports the care recipient to cope better with such situations by challenge or by a threat.

Effective caregiving behavior increases the likelihood of a much more strong relationship between the caregivers and care-recipient. Not only this, but it also enhances the care recipient's psychological well-being and the quality of the relationship. 


\section{Primary caregivers attitude towards patients with mental illness: a survey study in psychiatric centre, SMS medical college, Jaipur, Rajasthan, India}

Title III-E of the Older American Act Amendments of 2000, The National Family Caregiver Support Program, defined caregiver as--

"a family member or another individual, who is an 'informal' provider of in-home and community care to an individual."

There can be several characteristics of a caregiver. But most of the time, it can be the gender of the caregiver, religious belief (race \& ethnicity), the relation of a caregiver with the person-in-need, level of education, and cultural background irrespective of rural or urban living. All these can impact the attitude of a caregiver.

Caregivers are persons who do not perform medical care. Instead, they provide a personal touch. The recipient received help in daily-life activities as well as companionship. There are various kinds of Caregivers- Primary caregivers, Secondary caregivers, Working caregivers, Crisis caregivers, Long-distance caregivers, Community caregivers, and Future caregivers.

Here, in this study, it's surrounded by primary caregivers. Primary caregivers are the ones who routinely provide care for the loved one who is ill (in this case, mentally ill). They perform daily living activities of a recipient, such as bathing, dressing, taking care of medications.

Caregiving can be a challenging task in terms of mental \& emotional health. Like, they can be prone to have depression and a higher level of stress \& frustration. Moreover, the caregiver's physical health also gets affected. Like, increased risk of heart disease, low level of self-care, sometimes caregivers pay the ultimate price for providing care increases mortality.

In India, the family holds various sentiments and values.

REVIEW OF LITERATURE

Bhavesh Lakdawala \& Ganpat K. Vankar, 2016. They conducted a community-based study on mental health literacy amongst college students' of Gujarat. The findings were significant negative attitudes in students of all faculties. There were also perceptions of the mentally ill as a violent person. On treatment-related issues, psychotherapy (counseling) in psychology and sociology students had lower agreement than medical students are their main area of work dealing with the mentally ill. Many participants were not comfortable telling a friend, family member, or teacher about their mental health issues. These all suggest the need to improve mental health literacy in the students' population who are future mental health professionals.

Seema Parijaet. al. (2017) conducted a study on Indian nursing student's attitudes towards mental illness and persons with mental illness. The findings were showed high negative attitude in nursing students underline the need for strong anti-stigma measures. Differences in attitude toward mental illness in general and specific psychiatric conditions need further systematic evaluation.

Akshat Chowdhury \& et al. (2019) conducted a study on attitude, belief, and perception toward mental illness among Indian youth. The present study indicated that depression was easily recognizable as compared to schizophrenia among college students. Stressful factors 


\section{Primary caregivers attitude towards patients with mental illness: a survey study in psychiatric centre, SMS medical college, Jaipur, Rajasthan, India}

were considered the primary cause for both depression and schizophrenia. It concluded that the plurality had a negative attitude toward folk therapy, psychosocial manipulation, and physical method with a mental image of the family as the primary source for seeking help regarding mental illness. Also, participants had a belief that mental disorder is a cause for depression, and stress is the primary cause for schizophrenia among the mental illness. Therefore, the prognosis of both depression and schizophrenia was considered as good.

C Ruth Sneha et al. (2019) in their study as far as to assess the attitude and awareness about mental illness among a rural population in Kolar. The study concludes that its implications for social integration and management remain poor among the general public. Hence, the need for well-coordinated public education, mental health awareness programs, and increased accessibility of fruitful mental health services.

Shivani Mathur Gaiha \& et. al. (2020) conducted a study on a stigma associated with mental health problems among young people in India: a systematic review of magnitude, manifestations, and recommendations. Most studies (66\%) focused on youth training to become health professionals. One-third of young people display poor knowledge of mental health problems and negative attitudes towards people with mental health problems, and one in five had actual/intended stigmatizing behavior (I2>=95\%). Young people were ineffectual to recognize causes and symptoms of mental health problems and believe that recovery is unlikely. People with mental health problems are considered dangerous and irresponsible, likely due to misinformation and misunderstanding of mental health problems solely comprised of severe mental disorders (example- schizophrenia). However, psychiatric labels are not commonly used/understood. Public education may use symptomatic vignettes (through relatable language and visuals) instead of psychiatric labels to improve young people's understanding of the range of mental health problems. Recommended strategies to reduce public stigma include awareness campaigns integrated with educational institutions and content relevant to culture and age-appropriate social roles.

\section{METHODOLOGY}

Aim: To study the primary caregiver's attitudes towards mental illness.

\section{Objectives}

The purpose of this study is to assess the primary caregiver's attitude towards the person with mental illness among a sample of the informants of the patients in the psychiatric center, based on factors such age, gender, relation with the patient, religion, rural/urban belonging, age, educational qualification, employment level, and their marital status.

\section{Hypotheses}

H0: There will be no significant difference between the rural and urban people's attitudes towards mental illness.

H1: There will be a significant difference between the rural and urban people attitude towards mental illness

\section{Sample}

A total sample of 50 participants was there. All of them were from the psychiatry outpatient department (OPD) of the hospital. Out of which $(n=25)$ were males and $(n=25)$ were females. The age range of the participants was 18 to 65 years. The sample is from different regions of 3 North India states, both rural and urban populations included in this study. In 


\section{Primary caregivers attitude towards patients with mental illness: a survey study in psychiatric centre, SMS medical college, Jaipur, Rajasthan, India}

total, 75 participants were allowed to participate in the research, and 50 obliged. Caregivers of patients who were clinically diagnosed with some mental illness, attending the OPD for the first time for treatment, and having the purpose of the follow-up were involved in this study.

\section{Design}

The study had a between-group design with two groups; participants living in rural areas and in urban areas. The dependent variable is the case of the attitude of the participants towards mental health.

\section{Material}

For data collection, "The Community Attitudes Towards Mental Illness scale (CAMI)" was used. "CAMI" was developed by Taylor and Dear in 1981. It contains 40 questions about mental illness rated on a five-degree Likert-scale $(1=$ strongly agree to $5=$ strongly disagree). Negatively stated items were reverse recorded for analysis. The scale has four subscales, each with 10th items: Authoritarianism (AU), Benevolence (BE), Social Restrictiveness (SR), and Community Mental Health Ideology (CMHI). AU is a "view of the mentally ill person as someone who is inferior and requires supervision and coercion." BE corresponds to "a humanistic and sympathetic view of mentally ill persons"; SR means "the belief that mentally ill patients are a threat to society it should avoid." Community Mental Health Ideology (CMHI) is "the acceptance of mental health services and the integration of mentally ill patients in the community." Higher AU scores, lower BE scores, lower SR scores, and higher CMHI scores would indicate high stigma. Overall, stigma against patients with mental illness was computed by summing up the subscales. Higher scores indicate fewer stigma attitudes against patients with mental illness.

\section{Procedure}

To conduct a survey analysis of a standardized questionnaire (The Community Attitudes Towards Mental Illness scale (CAMI)) was used and interviewed by 50 participants randomly to provide an appropriate response. The participants were all randomly selected to avoid biases in the response. They were all directly interviewed through face-to-face interaction. There was no obligation to be a part of this study, participant's voluntary willingness to be a part of this study was taken prior. When the participants had completed the survey questionnaire form, they were all thanked.

\section{Statistical analysis}

The study followed the descriptive statistics using correlational research design and calculated using Microsoft Excel 2007.

Table 1: Demographic Variables

\begin{tabular}{|l|l|l|l|}
\hline Items & Detail & Frequency & Percentage \\
\hline \multirow{5}{*}{ Gender } & Male & $\mathbf{2 5}$ & $\mathbf{5 0}$ \\
\cline { 2 - 4 } & Female & $\mathbf{2 5}$ & $\mathbf{5 0}$ \\
\hline \multirow{5}{*}{ Age } & $18-24$ & 10 & $\mathbf{2 0}$ \\
\cline { 2 - 4 } & $25-31$ & $\mathbf{1 0}$ & $\mathbf{2 0}$ \\
\cline { 2 - 4 } & $\mathbf{3 2 - 3 8}$ & $\mathbf{1 4}$ \\
\hline & $\mathbf{3 9 - 4 5}$ & $\mathbf{5}$ & $\mathbf{1 0}$ \\
\cline { 2 - 4 } & $\mathbf{4 6 - 5 2}$ & $\mathbf{1 0}$ & $\mathbf{2 0}$ \\
\cline { 2 - 4 } & $\mathbf{5 3 - 5 9}$ & $\mathbf{1 0}$ & \\
\hline
\end{tabular}


Primary caregivers attitude towards patients with mental illness: a survey study in psychiatric centre, SMS medical college, Jaipur, Rajasthan, India

\begin{tabular}{|c|c|c|c|}
\hline Items & Detail & Frequency & Percentage \\
\hline & 60 and above & 3 & 6 \\
\hline \multirow{4}{*}{ Employment } & Employed & 27 & 54 \\
\hline & Unemployed & 10 & 20 \\
\hline & Home-maker & 11 & 22 \\
\hline & Retired & 2 & 4 \\
\hline \multirow[t]{2}{*}{ Marital status } & Married & 38 & 76 \\
\hline & Un-Married & 12 & 24 \\
\hline \multirow{3}{*}{ Education } & Primary & 16 & 32 \\
\hline & Secondary & 8 & 16 \\
\hline & Tertiary & 26 & 52 \\
\hline \multirow[t]{2}{*}{ Living background } & Rural & 25 & 50 \\
\hline & Urban & 25 & 50 \\
\hline \multirow{3}{*}{ Religion } & Hindu & 41 & 82 \\
\hline & Muslim & 7 & 14 \\
\hline & Sikh & 2 & 4 \\
\hline \multirow{23}{*}{$\begin{array}{l}\text { Relation with the } \\
\text { patient }\end{array}$} & \multicolumn{3}{|l|}{ Parent } \\
\hline & Mother & 4 & 8 \\
\hline & & 10 & 20 \\
\hline & \multicolumn{3}{|l|}{ Sibling/Cousin } \\
\hline & Sister & 4 & 8 \\
\hline & Brother & 7 & 14 \\
\hline & \multicolumn{3}{|l|}{ Children } \\
\hline & Daughter & 3 & 6 \\
\hline & Son & 7 & 14 \\
\hline & \multicolumn{3}{|l|}{ Spouse } \\
\hline & Wife & 3 & 6 \\
\hline & Husband & 2 & 4 \\
\hline & \multicolumn{3}{|c|}{ Grand-son/daughter } \\
\hline & Daughter & 2 & 4 \\
\hline & Son & 1 & 2 \\
\hline & \multicolumn{3}{|l|}{ Grand-parent } \\
\hline & Maternal & - & - \\
\hline & Paternal & 1 & 2 \\
\hline & \multicolumn{3}{|l|}{ In-laws } \\
\hline & Daughter-in-law & 1 & 2 \\
\hline & Sister-in-law & 4 & 8 \\
\hline & Brother-in-law & 1 & 2 \\
\hline & \multicolumn{3}{|l|}{$\mathrm{N}=\mathbf{5 0}$} \\
\hline
\end{tabular}

\section{RESULTS AND ANALYSIS}

To find out the contrast, in the attitude of the rural and the urban populations' comparison was made within these two categories from the CAMI scale. Several independent sample student $\mathrm{t}$-tests were applied, and the result is showed in a tabular presentation below. 
Primary caregivers attitude towards patients with mental illness: a survey study in psychiatric centre, SMS medical college, Jaipur, Rajasthan, India

Table 2 shows the mean scores of the four attitude categories of the CAMI scale among rural and urban populations with the t-test.

\begin{tabular}{|l|l|l|l|l|l|}
\hline Category & Background & N & M & SD & t \\
\hline \multirow{3}{*}{ Authoritarianism } & Rural & 25 & 33.20 & 3.47 & $0.92^{*}$ \\
\cline { 2 - 5 } & Urban & 25 & 33.09 & 4.42 & \\
\hline \multirow{2}{*}{ Social Restrictiveness } & Rural & 25 & 34.29 & 4.19 & \multirow{2}{*}{$0.21^{*}$} \\
\cline { 2 - 5 } & Urban & 25 & 35.72 & 3.49 & \\
\cline { 2 - 5 } & Rural & 25 & 27.53 & 2.94 & \multirow{2}{*}{$0.27^{*}$} \\
\cline { 2 - 5 } $\begin{array}{l}\text { Community mental } \\
\text { health ideology }\end{array}$ & Rural & 25 & 26.20 & 5.00 & \\
\cline { 2 - 5 } & Urban & 25 & 36.08 & 3.67 & $0.91^{*}$ \\
\hline
\end{tabular}

$* \mathrm{p}<0.05$

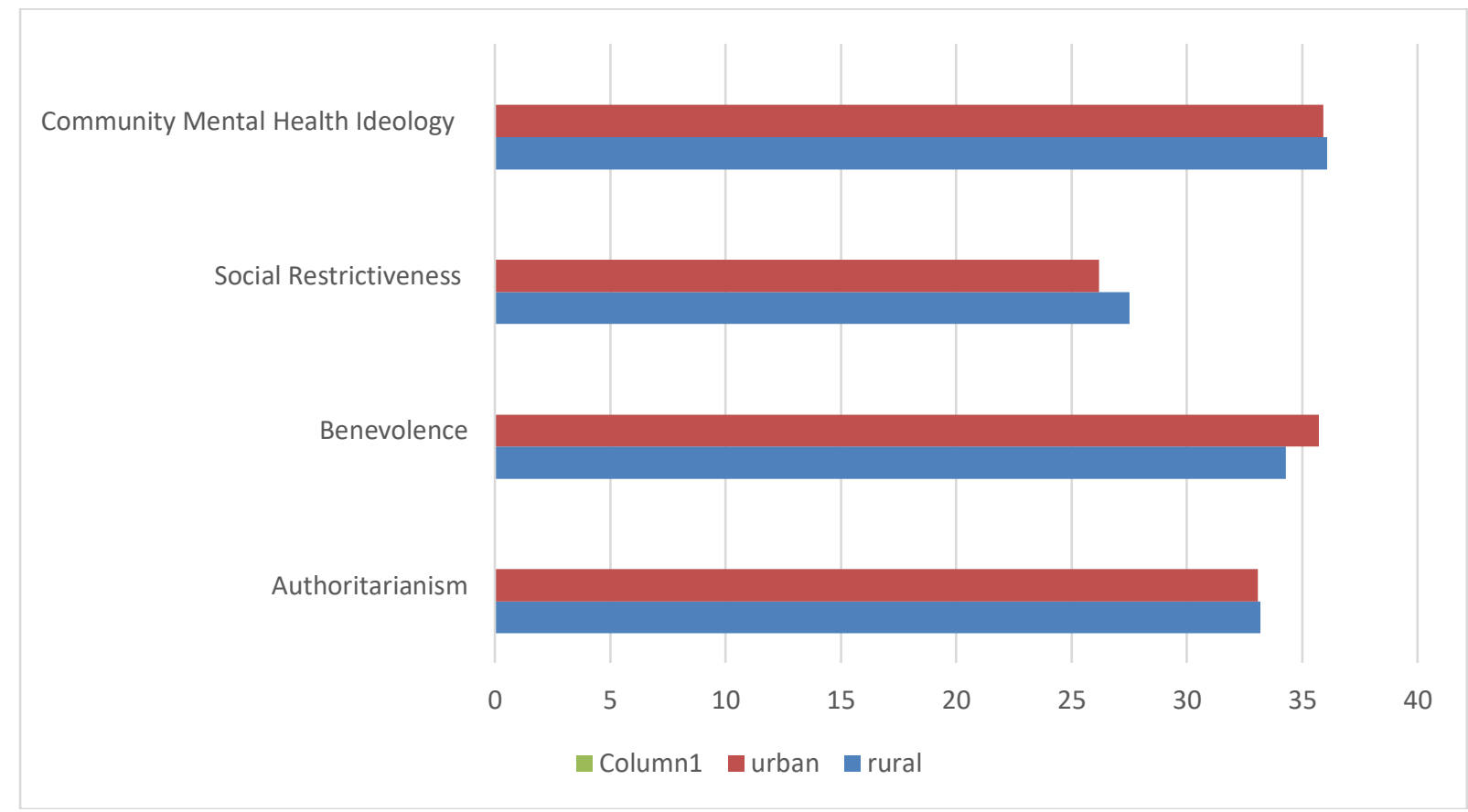

Figure 1. Graphical representation of mean scores

\section{Authoritarianism}

The rural participants $(M=33.20)$ responses to the question in this category did not differ much from the urban participants' $(\mathrm{M}=33.09)$ responses. It means that both participants have the same authoritative approach towards people with mental illness.

\section{Benevolence}

The rural participants $(M=34.29)$ responses to the question in this category differed from the urban participants' $(\mathrm{M}=35.72)$ responses. It means that the urban participants have a higher sense of goodwill towards people with mental illness.

\section{Social Restrictiveness}

The rural participants $(M=27.53)$ responses to the question in this category differed from the urban participants' $(M=26.20)$ responses. It means that the rural participants considered mentally ill are a danger to themselves and others. 


\section{Primary caregivers attitude towards patients with mental illness: a survey study in psychiatric}

centre, SMS medical college, Jaipur, Rajasthan, India

\section{Community mental health ideology}

The rural participants $(M=36.083)$ responses to the question in this category differed from the urban participants' $(M=35.93)$ responses. It implies that the rural population considered it scary to think that mentally ill people live in the neighborhood.

Table 3 shows the correlation between the four sub-categories of the CAMI Test.

\begin{tabular}{|l|l|l|l|l|}
\hline & Authoritarianism & Benevolence & $\begin{array}{l}\text { Social } \\
\text { Restrictiveness }\end{array}$ & $\begin{array}{l}\text { Community } \\
\text { Mental } \\
\text { Health } \\
\text { Ideology }\end{array}$ \\
\hline Authoritarianism & 1 & -.060 & .202 & .113 \\
\hline Benevolence & -.060 & 1 & .005 & .038 \\
\hline $\begin{array}{l}\text { Social } \\
\text { Restrictiveness }\end{array}$ & .202 & .005 & 1 & -.197 \\
\hline $\begin{array}{l}\text { Community Health } \\
\text { Mental Heogy } \\
\text { Ideology }\end{array}$ & .113 & .038 & -.197 & 1 \\
\hline \begin{tabular}{l} 
(N=50) \\
\hline
\end{tabular} & & & \\
\hline
\end{tabular}

$(N=50)$

The correlations in the above table suggest that the attitude is not independent of each other. The highest inter-dimension correlation $(\mathrm{r}=.202)$ being between the two categories of Authoritarianism and Social Restrictiveness (Table 3). The lowest inter-dimension correlation $(\mathrm{r}=.005)$ being between the two dimensions of Benevolence and Social Restrictiveness. (Table 3).

\section{DISCUSSION}

This study aims to study the attitudes of primary-care givers towards mental illness. "Community Attitudes Towards Mental Illness scale (CAMI)" was used. Administration of the scale was done through interviews to collect the data, to avoid discrepancy in the scores. Personal data consist of demographic information was also collected.

Stigma was defined by Goffman (1970) as the position of the individual who is disqualified from full social acceptance. The outcome of a process of social labeling which singles out the difference, names this difference inferiority, subsequently blames those who are different for their otherness and contributes to the creation of a spoilt identity (Goffman 1970). Mental illnesses are health conditions involving changes in emotion, thinking, or behavior (or a combination of these). Mental illnesses are associated with distress or problems functioning in social, work, or family activities. (American Psychiatric Association, 2018) Overall, in this study, rural people hold a high stigma against the person with mental illness. Null hypothesis (H0) is rejected here, and the alternative hypothesis (H1) is accepted which state that there will be a significant difference between the rural and urban people attitude towards mental illness.

Romany H. Gabra, Omnya S. Ebrahim, Doaa M. M. Osman \& Ghada S. T. Al-Attar (2020) conducted a study on the knowledge, attitude, and health-seeking behavior among family caregivers of mentally ill patients at Assiut University Hospitals. In the study, the results were that the caregivers had low scores of knowledge and attitude towards mental illness. Age of the caregivers, their education and the type of first consulted care, and their aggressive behavior of the mentally ill relatives were the significant predictors of caregivers' 


\section{Primary caregivers attitude towards patients with mental illness: a survey study in psychiatric centre, SMS medical college, Jaipur, Rajasthan, India}

knowledge and attitude towards mental illness. The majority of caregivers (80.2\%) sought advice for the first time from traditional healers. Traditional healers referred only $16.4 \%$ of caregivers' mentally ill relatives to psychiatric care.

They studied caregivers who had poor knowledge and a negative attitude towards mental illness. Traditional healers were the only consulted care. So, increasing awareness of mental illness is highly recommended (Romany H. Gabra, Omnya S. Ebrahim, Doaa M. M. Osman \& Ghada S. T. Al-Attar, 2020).

Shrabani Mukherjee and Dipta Kanti Mukhopadhyay (2018) conducted a hospital-based cross-sectional study among caregivers (West-Bengal) to find the stigma towards mental illness.

The average stigma score $(53.3 \pm 13.2)$ was higher than $50 \%$ of the maximum attainable score. Caregivers of higher age, female gender, low income, higher education, manual job, rural residence, and single or widowed scored higher on the stigma scale. Caregivers with female gender $(\mathrm{P}=0.007)$ and rural population $(\mathrm{P}=0.01)$ were more likely to have a stigma, while the perception score was negatively associated $(\mathrm{P}<0.001)$ with the stigma score. The study highlighted that health-care providers play a pivotal role in the caregivers' stigma to alleviate its effect on the course of illness and improve family life. (Shrabani Mukherjee and Dipta Kanti Mukhopadhyay, 2018).

Here, I safely conclude a significant difference between the rural and urban people's attitudes towards mental illness.

\section{CONCLUSION}

The results show differences in attitudes towards mental illness between two populations, the rural and urban, in the four attitude categories Authoritarianism, Benevolence, Social Restrictiveness, and Community Mental Health Ideology.

\section{Limitations and Implications}

- It is recommended, for future research, the number of participants should be large in number.

- The finding of this research is that it can use to get a better understanding of the stigma attached to mental illness in society

\section{REFERENCES}

Ahmedani B. (2011). Mental health stigma: society, individuals, \& the profession. Journal of Social Work Values Ethics, Vol-8(2), PMCID: PMC3248273, NIHMSID: NIHMS342711, PMID: 22211117

Attitude: definition, nature \& characteristics (explained) (n.d.) Retrieved from https://www.iedunote.com/attitude-definition-characteristics-types

Bhatia A. (2020). World mental health day 2020: In numbers, the burden of mental disorders in India (n.d.) Retrieved from https://swachhindia.ndtv.com/world-mental-healthday-2020-in-numbers-the-burden-of-mental-disorders-in-india-51627/

Caregiving: How to avoid burnout stress (n.d.) Retrieved from https://www.medicinenet.com/caregiving/article.htm\#what_is_caregiver_stress 


\section{Primary caregivers attitude towards patients with mental illness: a survey study in psychiatric centre, SMS medical college, Jaipur, Rajasthan, India}

Chowdhary A., Gupta K., \& Patel A. (2019). Attitude, belief, and perception toward mental illness among Indian youth. MAMC Journal of Medical Sciences, Vol-5, Issue-2, Page 83-88

Common mental illness (2020) (n.d.) Retrieved from https://www.whiteswanfoundation.org/mental-health-matters/understanding-mentalhealth/common-mental-disorders

Felman A., (2020). What is mental health? Definition, risk factors, related disorders, early signs, treatment (n.d.) Retrieved from https://www.medicalnewstoday.com/articles/154543\#: :text=Mental\%20health\%20r efers $\% 20$ to $\% 20$ cognitive, $\% 2 \mathrm{C} \% 20$ relationships $\% 2 \mathrm{C} \% 20$ and $\% 20$ physical $\% 20$ health

Gabra R., Ebrahim O., Osman D \& Al-attar G. (2020). Knowledge, attitude and healthseeking behavior among family caregivers of mentally ill patients at Assiut University Hospitals: a cross-sectional study. Article number: 10 (2020)

Introduction to Caregiving (n.d.) Retrieved from https://www.whiteswanfoundation.org/caregiving/introducing-caregiving

Lefley H. (1996). Family Caregiving in Mental Illness. Sage publications inc. Vol-7, ISBN: 9780803957213

Luitel P., Jordan D., Subba P., \&Komproe I. (2020). Perception of service users and their caregivers on primary care-based mental health services: a qualitative study in Nepal. BMC Family Practice, Article number-202(2020)

Mukherjee S. \&Mukhopadhyay D. (2018) Stigma towards mental illness: A hospital-based cross-sectional study among caregivers in West Bengal, VOL-62, Issue-1, Page 1520

Naeem Z. (2011). Factors affecting attitudes: a study of immigrant attitude towards the brochures \& website of VaxjoKommun, Bachelor thesis, Spring 2011

Neupane D., Shakal S., Thapa S., Bhandari P \& Mishra S. (2016). Caregivers' attitude towards people with mental illness and perceived stigma: A cross-sectional study in a tertiary hospital in Nepal. PLoS One Vol-11(6), DOI: 10.1371/journal.pone.0158113

Oncolink Team (2020). Caregiving Basics (n.d.) Retrieved from https://www.oncolink.org/support/caregivers/caregiving-basics

Paliwal S. (2013). Social Psychology. RBSA Publishers, ISBN 81-7611-3666-2

Pavitra S., Kalmane S., Kumar A., \&Gowdia M. (2019). Family matters! - the caregivers' perspective of mental health care act 2017. Indian Journal of Psychiatry, Vol-61, Issue-10, Page 832-837

Raghuram A., Verma N., \& Maridass A. (1984). Public attitudes toward mental illness: a review. NIMHANS Journal, Vol-02, Issue-01, Page 1-14

Salve H., Goswani K., Sagar R., Nongkyumn B., \& Sreenvas V. (2013). Perception \& attitude towards mental illness in an urban community in South Delhi: a communitybased study. Indian Journal of Psychological Medicine, Vol-35(2), PMICID: PMC3775047, DOI: 10.4103/0253-7176.116244

Sarason I., \&Sarason B. (2005). Abnormal psychology- the problem of maladaptive behavior, $11^{\text {th }}$ edition. Pearson Education Inc., New Jersey 07458. ISBN- 978-81203-2663-7

Sneha C., Reddy M., Nongmeikapam M., \&Naryana J. (2019). Awareness and attitude toward mental illness among a rural population in Kolar. Indian Journal of Social Psychiatry, Vol-35, Issue-1, Page 69-74.

Sreeraj V., Parija S., Uvais N, Mohanty S., \& Kumar S. (2017). Indian nursing student's attitudes toward mental illness and persons with mental illness. Industrial Psychiatry Journal. DOI: 10.4103/in.ipj_25_16 
Stein D., Phillips K., Bolton D., Fulford K., Saddler J \&Kundler K. (2010). What is a mental/psychiatric disorder? From DSM-IV to DSM-V. Psychol Medicine, Vol40(11), DOI: 10.1017/S0033291709992261

Trani J, Bakhshi P, Kuhlberg J, et al. Mental illness, poverty and stigma in India: a casecontrol study BMJ Open 2015;5: e006355. DOI: 10.1136/BMJ open-2014-006355

What is mental health? A brief introduction to mental health (n.d.) Retrieved from https://www.whiteswanfoundation.org/mental-health-matters/understanding-mentalhealth/what-is-mental-health

Zopp L. (2020). What is mental health stigma? (n.d.) Retrieved from https://www.medicalnewstoday.com/articles/mental-health-stigma

\section{Acknowledgement}

The author appreciates all those who participated in the study and helped to facilitate the research process.

\section{Conflict of Interest}

The author declared no conflict of interest.

How to cite this article: Sharma T., Singh P. \& Phulwari H. (2021). Primary caregivers attitude towards patients with mental illness: a survey study in psychiatric centre, SMS medical college, Jaipur, Rajasthan, India. International Journal of Indian Psychology, 9(1), 1209-1220. DIP:18.01.126/20210901, DOI:10.25215/0901.126 